\title{
Small Molecule Drug Candidates for Managing the Clinical Symptoms of COVID-19: a Narrative Review
}

\author{
Chawon Yun ${ }^{1}$, Hyun Jae Lee ${ }^{2, *}$ and Choong Jae Lee ${ }^{1, *}$ \\ ${ }^{1}$ Department of Pharmacology, School of Medicine, Chungnam National University, Daejeon 35015, \\ ${ }^{2}$ Smith Liberal Arts College and Department of Addiction Science, Graduate School, Sahmyook University, Seoul 01795, Republic of \\ Korea
}

\begin{abstract}
Towards the end of 2019, an atypical acute respiratory disease caused by severe acute respiratory syndrome coronavirus 2 (SARS-CoV-2) was identified in Wuhan, China and subsequently named Coronavirus disease 2019 (COVID-19). The rapid dissemination of COVID-19 has provoked a global crisis in public health. COVID-19 has been reported to cause sepsis, severe infections in the respiratory tract, multiple organ failure, and pulmonary fibrosis, all of which might induce mortality. Although several vaccines for COVID-19 are currently being administered worldwide, the COVID-19 pandemic is not yet effectively under control. Therefore, novel therapeutic agents to eradicate the cause of the disease and/or manage the clinical symptoms of COVID-19 should be developed to effectively regulate the current pandemic. In this review, we discuss the possibility of managing the clinical symptoms of COVID-19 using natural products derived from medicinal plants used for controlling pulmonary inflammatory diseases in folk medicine. Diverse natural products have been reported to exert potential antiviral effects in vitro by affecting viral replication, entry into host cells, assembly in host cells, and release. However, the in vivo antiviral effects and clinical antiviral efficacies of these natural products against SARS-CoV-2 have not been successfully proven to date. Thus, these properties need to be elucidated through further investigations, including randomized clinical trials, in order to develop optimal and ideal therapeutic candidates for COVID-19.
\end{abstract}

Key Words: Natural products, Coronavirus, SARS-CoV-2, COVID-19

\section{INTRODUCTION}

As we perceive, towards the end of 2019 , Coronavirus disease 2019 (COVID-19) was discovered in Wuhan, China. The cause of the disease was identified as severe acute respiratory syndrome coronavirus 2 (SARS-CoV-2). The rapid dissemination of COVID-19 has provoked a global crisis in public health, with the World Health Organization (WHO) having declared COVID-19 a global pandemic by March 2020 (Zhu et al., 2020).

The clinical staging of COVID-19 includes asymptomatic, mild, moderate, severe, and critical forms of the disease. In the case of mild SARS-CoV-2 infection, patients might experience dry cough, fever, nasal congestion, muscle pain, and tiredness. In critical cases, COVID-19 provokes sepsis, acute severe infections in the respiratory tract, multiple organ failure, and pulmonary fibrosis. Following exposure to SARS-CoV-2, alveolar damage and initiation of pulmonary fibrosis might occur during the incubation period of 2-3 weeks. As a result, patients with COVID-19 present with sputum expectoration and shortness of breath. Older patients have a greater chance of developing severe or critical forms of the disease, especially those with chronic illnesses including hypertension, cardiovascular diseases, diabetes mellitus, and cerebrovascular diseases (Gustine and Jones, 2021).

Although the vaccines currently in use for immunization against COVID-19 include at least thirteen preparations (classified as four platforms) that are expected to be safe and efficacious for the prevention of severe/critical illness, the status of the pandemic has not yet been effectively controlled worldwide (Gumel et al., 2021). Therefore, novel therapeutic agents that can eradicate the core cause of the disease or

\section{Open Access https://doi.org/10.4062/biomolther.2021.134}

This is an Open Access article distributed under the terms of the Creative Commons Attribution Non-Commercial License (http://creativecommons.org/licenses/by-nc/4.0/) which permits unrestricted non-commercial use, distribution, and reproduction in any medium, provided the original work is properly cited.
Received Aug 11, 2021 Revised Sep 10, 2021 Accepted Sep 15, 2021 Published Online Oct 7, 2021

\section{*Corresponding Authors}

E-mail: hjy1213@syu.ac.kr (Lee HJ), LCJ123@cnu.ac.kr (Lee CJ) Tel: +82-2-3399-1910 (Lee HJ), +82-42-580-8255 (Lee CJ) Fax: +82-2-3399-1909 (Lee HJ), +82-42-585-6627 (Lee CJ) 
Table 1. Chemical and biological preparations investigated for the management and/or treatment of COVID-19 to date

\begin{tabular}{|c|c|}
\hline $\begin{array}{l}\text { Classification of chemical and } \\
\text { biological preparations }\end{array}$ & Agents \\
\hline \multirow[t]{2}{*}{ Glucocorticosteroids } & Dexamethasone (Bartoletti et al., 2021) \\
\hline & Methylprednisolone (Hu et al., 2020) \\
\hline \multirow[t]{6}{*}{ Antiviral agents } & Umifenovir (Khamitov et al., 2008; Kadam and Wilson, 2017) \\
\hline & Ribavirin (Foolad et al., 2019) \\
\hline & Lopinavir (Chu et al., 2004) \\
\hline & Ritonavir (Chu et al., 2004) \\
\hline & Favipiravir (Mentré et al., 2015) \\
\hline & Remdesivir (Siegel et al., 2017) \\
\hline \multirow[t]{5}{*}{ Antimalrarial/Antihelminthic agents } & Nitazoxanide (Rossignol, 2016) \\
\hline & Chloroquine (Savarino et al., 2003; Al-Bari, 2017) \\
\hline & Hydroxychloroquine (Savarino et al., 2003; Al-Bari, 2017) \\
\hline & Pyronaridine (Krishna et al., 2021) \\
\hline & Artesunate (Krishna et al., 2021) \\
\hline \multirow[t]{6}{*}{ Immunomodulators } & Tocilizumab (Xu et al., 2020) \\
\hline & Baricitinib (Goletti and Cantini, 2021) \\
\hline & Imatinib (de Wilde et al., 2011; La Rosée et al., 2020; Li and De Clercq, 2020) \\
\hline & Dasatinib (de Wilde et al., 2011; La Rosée et al., 2020; Li and De Clercq, 2020) \\
\hline & Cyclosporine (de Wilde et al., 2011; La Rosée et al., 2020; Li and De Clercq, 2020) \\
\hline & Ruxolitinib (de Wilde et al., 2011; La Rosée et al., 2020; Li and De Clercq, 2020) \\
\hline \multirow{2}{*}{$\begin{array}{l}\text { Inhibitors for the human transmembrane } \\
\text { surface protease, TMPRSS2 }\end{array}$} & Camostat (Hoffmann et al., 2020; Breining et al., 2021) \\
\hline & Nafamostat (Hoffmann et al., 2020; Breining et al., 2021) \\
\hline
\end{tabular}

at least manage the clinical symptoms of COVID-19, should be developed to effectively control the global pandemic. The present recommendations of potential therapeutics for managing COVID-19 are based on empirical and historical data from various viral infections, including other types of SARSCoV infections. In addition, drug repositioning techniques and virtual drug development tools have been utilized for making such recommendations (Jang et al., 2021). However, cuttingedge drug candidates have not yet been developed to date (Table 1).

On the other hand, natural products have been reported to exert a broad range of pharmacological effects and can thus be potentially developed as novel agents to treat various diseases. Some natural products have shown antiviral effects and consequently been utilized as prototypes during the development of novel antiviral agents.

In this context, in the current review, we attempt to discuss and rationalize the possibility of managing the clinical symptoms of COVID-19 using natural products derived from medicinal plants used for controlling pulmonary inflammatory diseases in folk medicine, based on a multitude of original research articles (Fig. 1).

\section{CHEMICAL AND BIOLOGICAL PREPARATIONS INVESTIGATED FOR THE MANAGEMENT AND/OR TREATMENT OF COVID-19 TO DATE}

\section{Glucocorticosteroids}

Because COVID-19 incites a multitude of systemic inflammatory reactions including severe pulmonary inflammation, glucocorticoids, which are a group of potent anti-inflammatory

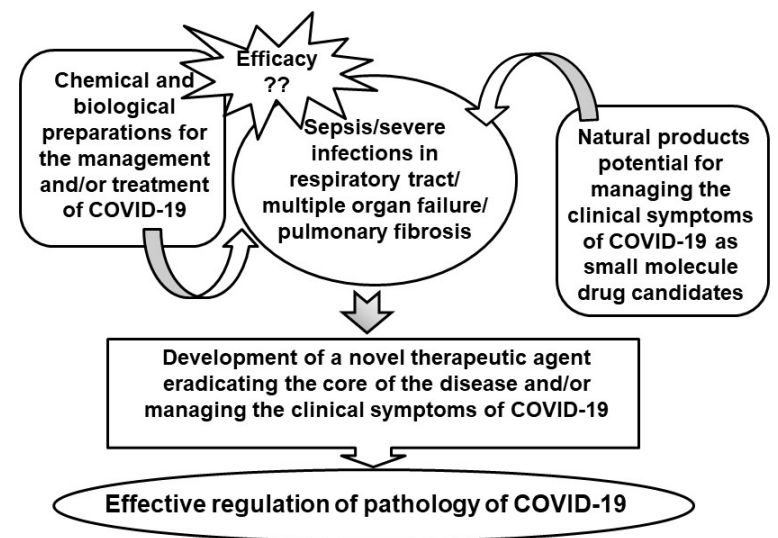

Fig. 1. Strategy for developing novel therapeutic agents for eradicating the core cause of the disease and/or managing the clinical symptoms of COVID-19. The COVID-19 pandemic has not been effectively controlled globally. Thus, novel therapeutic agents that can eradicate the core cause of the disease and/or manage the clinical symptoms of COVID-19 should be developed to effectively regulate the spread of the virus. Diverse natural products have been reported to exert antiviral properties in vitro by affecting viral replication, viral entry into host cells, viral assembly in host cells, and viral release. The in vivo antiviral effects and clinical antiviral efficacies of these natural products against SARS-CoV-2 should be further elucidated through rigorous investigations to develop optimal and ideal therapeutic candidates for COVID-19.

agents, might be a useful therapeutic option. However, chronic and/or megadose administration of glucocorticoids has been attributed to various adverse effects, including depression of 
immune function, hyperglycemia, lipodystrophy, and osteoporosis (Fardet and Fève, 2014; Ni et al., 2019). According to several clinical trials, the administration of dexamethasone to patients with COVID-19 who required oxygenation resulted in a decrease in death rates (Bartoletti et al., 2021). Administration of a low dose of glucocorticoids during a short period mitigated inflammation and retarded the progression of the disease (Hu et al., 2020). However, due to the adverse effects of glucocorticoids, including depressed immune function, a probable risk of aggravation of the disease exists, and there is no definite guarantee that chronic administration of glucocorticoids protects the human body from SARS-CoV-2 infection and the development of severe COVID-19 (Hu et al., 2020; Bartoletti et al., 2021).

\section{Umifenovir, Ribavirin, Lopinavir, Ritonavir, Favipiravir}

Umifenovir blocks the interaction between viral spike proteins and human angiotensin-converting enzyme 2 (Khamitov et al., 2008; Kadam and Wilson, 2017). Ribavirin showed the possibility of suppressing the proliferation of SARS-CoV-2 by inhibiting the activity of RNA-dependent RNA polymerase (Foolad et al., 2019). Lopinavir and ritonavir, both anti-HIV antiviral agents, have been shown to suppress the proliferation of SARS-CoV-2 by inhibiting 3-chymotrypsin-like proteases (Chu et al., 2004). Favipiravir is a prodrug of favipiravir ribofuranosyl-5'-triphosphate and has been reported to block viral replication by inhibiting the activity of RNA polymerase (Mentré et al., 2015). However, to date, clinical trials have not proven these agents to be effective in treating COVID-19.

Table 2. Natural products potential for managing the clinical symptoms of COVID-19

\begin{tabular}{|c|c|}
\hline $\begin{array}{l}\text { Classification of } \\
\text { natural products }\end{array}$ & Compounds and their mechanisms of action \\
\hline \multirow[t]{7}{*}{ Flavonoids } & Apigenin (alleviates pulmonary injury through decreasing the levels of TGF- $\beta 1$ and TNF- $\alpha$ ) \\
\hline & Baicalin (prevents the interaction of S-protein of SARS-CoV with host angiotensin-converting enzyme 2) \\
\hline & Chalcones (suppresses the activity of proteases of SARS-CoV) \\
\hline & Kaempferol (suppresses the release of SARS-CoV from the infected cells by inhibition of the $3 a$ ion channel) \\
\hline & Luteolin (inhibits the entry of SARS-CoV into host cells through binding to the surface spike protein) \\
\hline & $\begin{array}{l}\text { Quercetin (suppresses the entry of SARS-CoV into the cell and the activity of SARS-3CLpro, a viral } \\
\text { replication enzyme) }\end{array}$ \\
\hline & $\begin{array}{l}\text { Scutellarein (suppresses the activity of the SARS coronavirus helicase, nsP13, through controlling ATPase } \\
\text { activity) }\end{array}$ \\
\hline \multirow[t]{9}{*}{ Alkaloids } & Cepharanthine (mitigates viral $\mathrm{S}$ and $\mathrm{N}$ proteins expression, thereby decreasing the replication of virus) \\
\hline & Fangchinoline (decreases viral $\mathrm{S}$ and $\mathrm{N}$ proteins expression, thereby decreasing the replication of virus) \\
\hline & $\begin{array}{l}\text { Homoharringtonine (suppresses infection by coronavirus through affecting the replication of coronavirus and } \\
\text { inhibits viral protein synthesis) }\end{array}$ \\
\hline & Indigo (suppresses the activity of 3CLpro, a viral replication enzyme) \\
\hline & Lycorine (suppresses the replication of SARS-CoV by interfering viral RNA translation) \\
\hline & Oxysophoridine (inhibits the replication of SARS-CoV-2) \\
\hline & Tryptanthrin (inhibits the replication of human coronavirus) \\
\hline & Tetrandrine (inhibits viral S and N protein expressions, thereby decreasing the replication of the virus) \\
\hline & $\begin{array}{l}\text { Tylophorine (suppresses the virulence of SARS-CoV by inhibiting the replication of virus and apoptosis of } \\
\text { host cells induced by virus) }\end{array}$ \\
\hline \multirow[t]{12}{*}{$\begin{array}{l}\text { Other groups including } \\
\text { triterpenoids }\end{array}$} & $\begin{array}{l}\text { Ascorbic acid (exerts immunomodulating, antifibrotic, antioxidative activities, and protective effects against } \\
\text { pulmonary infections) }\end{array}$ \\
\hline & Astragalosides (suppresses the production of nitric oxide and the release of pro-inflammatory cytokines) \\
\hline & Bananin (suppresses SARS-CoV NTPase/helicase and the replication of SARS-CoV) \\
\hline & Cinanserin (suppresses the replication of SARS-CoV) \\
\hline & Cinnamaldehyde (inhibits proteolytic activation of spike protein in SARS-CoV-2 by proteases in host cells) \\
\hline & Curcumin (protects acute lung injury, pulmonary fibrosis, and acute respiratory distress syndrome) \\
\hline & $\begin{array}{l}\text { Diallyl thiosulfonate (exerts controlling effects on edema of alveolar inner region, pulmonary fibrosis, } \\
\text { infections of respiratory tract, acute lung injury, and sepsis) }\end{array}$ \\
\hline & $\begin{array}{l}\text { Emodin (suppresses the interaction between SARS-CoV spike protein and host angiotensin-converting } \\
\text { enzyme } 2 \text { and the release of coronavirus from infected cells) }\end{array}$ \\
\hline & Glycyrrhizin (inhibits the replication, adsorption, and penetration of coronavirus) \\
\hline & Nimbolide (mitigates lung injury and pulmonary fibrosis) \\
\hline & Piperine (exerts anti-inflammatory, antiviral, and antioxidative activities) \\
\hline & Saikosaponins (inhibits the penetration and attachment of human coronavirus) \\
\hline
\end{tabular}




\section{Remdesivir}

Remdesivir is a monophosphate prodrug that is converted to an analog of adenosine nucleoside trisphosphate after being metabolized in the human body. It blocks the normal replication steps of viruses, including SARS-CoV-2, by being involved in the viral replication process (Siegel et al., 2017). In 2020, remdesivir was approved for the treatment of COVID-19 by the United States Food and Drug Administration (FDA) through emergency use authorization, with full approval being granted subsequently (Baracco, 2021). However, the shortcomings of this agent are that it should be administered by injection, and the cost of treatment is very high.

\section{Nitazoxanide, Chloroquine, Hydroxychloroquine, Pyronaridine, Artesunate}

Nitazoxanide is an anti-helminthic agent that shows antiviral effects against diverse viruses, including SARS-CoV-2 (Rossignol, 2016). Chloroquine and hydroxychloroquine have been utilized as antimalarial drugs and immunomodulators for the regulation of chronic inflammatory diseases. They block viral entry into host cells by inhibiting the glycosylation of host cell receptors, proteolytic processing, and endosomal acidification (Savarino et al., 2003; Al-Bari, 2017). A mixture of the antimalarial drugs, pyronaridine and artesunate, has been investigated as an anti-SARS-CoV-2 agent based on the assumption that the actions of the drugs are similar to those of chloroquine and hydroxychloroquine (Krishna et al., 2021). However, none of these agents have been proven to be effective and safe in the treatment of COVID-19, despite undergoing clinical trials.

\section{Tocilizumab, Baricitinib, Imatinib, Dasatinib, Cyclosporine, Ruxolitinib}

Tocilizumab is a monoclonal antibody against the interleukin-6 (IL-6) receptor. It is used as an anti-inflammatory agent in patients with rheumatoid arthritis and as an immune function modulator. Tocilizumab might be an effective therapeutic candidate for COVID-19 because the levels of IL-6 are elevated in patients with COVID-19 (Xu et al., 2020). In addition, baricitinib, imatinib, dasatinib, ruxolitinib, and cyclosporine are immunomodulators that inhibit SARS-CoV-2 activity. However, tocilizumab failed to show efficacy in decreasing mortality in hospitalized patients with COVID-19, while Janus kinase (JNK) pathway inhibitors including ruxolitinib and other immunomodulators have not been proven to be effective and safe in treating patients with COVID-19, despite undergoing clinical trials (de Wilde et al., 2011; La Rosée et al., 2020; Li and De Clercq, 2020). Recently, among the aforementioned agents, baricitinib was authorized for the emergency treatment of COVID-19 by the FDA through emergency use authorization (Goletti and Cantini, 2021).

\section{Camostat, Nafamostat}

For SARS-CoV-2 to enter the host cell, the human transmembrane surface protease TMPRSS2 cleaves and activates the spike proteins of the virus. The serine protease inhibitors, camostat and nafamostat, demonstrated an inhibitory effect towards the activity of TMPRSS2. Owing to this, these two agents are expected to show potential antiviral activity against SARS-CoV-2. However, their clinical efficacy and safety in treating COVID-19 have not yet been proven (Hoffmann et al., 2020; Breining et al., 2021).

\section{NATURAL PRODUCTS FOR POTENTIALLY MANAGING CLINICAL SYMPTOMS OF COVID-19}

In this section of the review, we discuss and rationalize the possibility of managing the clinical symptoms of COVID-19 using natural products derived from medicinal plants used for controlling pulmonary inflammatory diseases in folk medicine (Table 2). As can be seen in the sections to follow, diverse natural products have been reported to exert antiviral effects by affecting viral replication, entry into host cells, assembly in host cells, and release (Fig. 2).

\section{FLAVONOIDS}

\section{Apigenin}

Apigenin, a natural product, has antioxidant, antiviral, antiinflammatory, and antifibrotic effects (Kumar and Pandey, 2013; Suleria et al., 2015; Marefati et al., 2018). Apigenin was found to suppress pulmonary fibrosis by mitigating the infiltration of inflammatory cells and decreasing the fibronectin and hydroxyproline levels and deposition of collagen in animal models of lung fibrosis. Apigenin also decreased the expression of myeloperoxidase (MPO), a leukocyte adhesion marker, and increased the activity of superoxide dismutase. Furthermore, apigenin was reported to alleviate pulmonary injury by decreasing the levels of TGF- $\beta 1$ and TNF- $\alpha$ (Chen and Zhao, 2016; Shahabi et al., 2019). These biological activities of apigenin suggest its potential for development into an agent that manages lung injury, acute respiratory tract infections, and pulmonary fibrosis, all of which are symptoms that are presented in patients with COVID-19.

\section{Baicalin}

SARS-CoV-2 exploits the angiotensin-converting enzyme 2 receptor of the host to enter the host cell. Baicalin, a natural

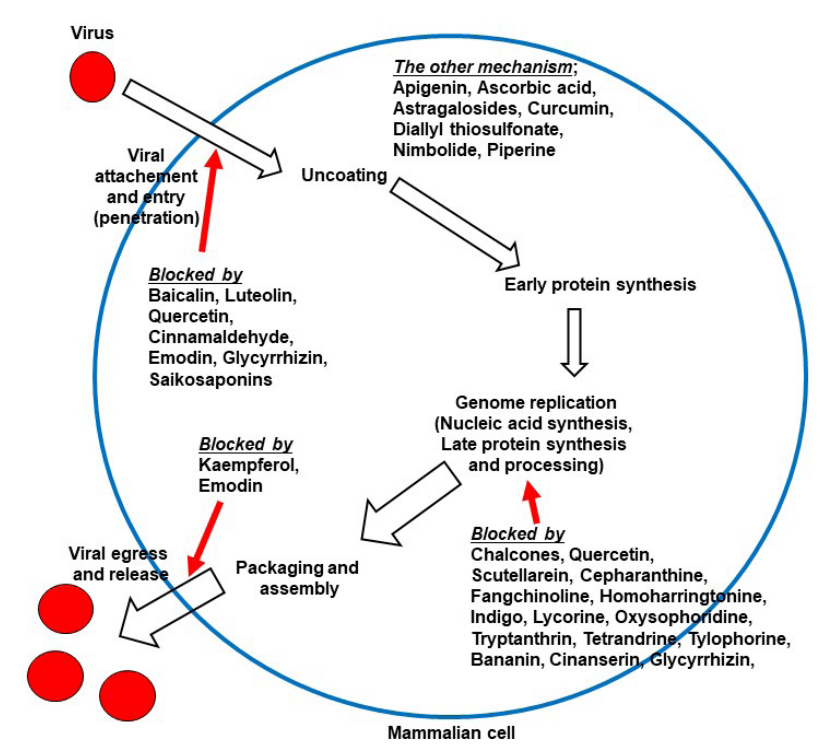

Fig. 2. The viral life cycle and the major action sites of natural products potential for eradicating the core cause of the disease and/or managing the clinical symptoms of COVID-19. 
product derived from Scutellaria baicalensis, was reported to prevent the interaction between the S protein of SARS-CoV and the angiotensin-converting enzyme 2 of the host (Chen and Nakamura, 2004; Deng et al., 2012).

\section{Chalcones}

It was reported that a papain-like protease (PLpro) and a chymotrypsin-like protease (3CLpro) are viral proteases of SARS-CoV. These enzymes are viral replication enzymes involved in converting replicase polypeptides of coronaviruses into functional proteins. Chalcones derived from Angelica keiskei showed potential as anti-SARS-CoV agents by suppressing the activity of these proteases (Park et al., 2016).

\section{Kaempferol}

The derivatives of kaempferol, a natural product, suppressed the function of the $3 a$ ion channel of SARS-CoV. It was postulated that the suppression of the $3 a$ ion channel interferes with the release of the coronavirus from infected cells (Schwarz et al., 2014).

\section{Luteolin}

Luteolin, a flavonoid compound, showed anti-SARS-CoV activity in a wild-type SARS-CoV infection system. As a possible mechanism of action of this natural product, luteolin has the potential to inhibit the entry of SARS-CoV into host cells by binding to the surface spike protein of the virus (Yi et al., 2004).

\section{Quercetin}

Quercetin showed antiviral activity against various viruses, including murine coronaviruses (Chiow et al., 2016). Quercetin has been reported to suppress the entry of SARS-CoV into the cell (Chen et al., 2008) and inhibit the activity of SARS3CLpro (Jo et al., 2020). 3CLpro is a viral replication enzyme that catalyzes the processing of replicase polypeptides of coronavirus into functional proteins. Quercetin was found to suppress pulmonary fibrosis by preventing the infiltration of inflammatory cells and deposition of collagen and depleting the fibronectin and hydroxyproline levels in animal models of lung fibrosis. It was also reported to reduce the damage to pulmonary tissues by decreasing the biological markers of oxidative stress and inflammation (Farazuddin et al., 2018; Zhang et al., 2018). These biological activities of quercetin suggest its potential for development into an agent that regulates lung injury, acute respiratory tract infections, and pulmonary fibrosis, all of which are symptoms observed in patients with COVID-19.

\section{Scutellarein}

The helicase protein in coronaviruses might be a pharmacological target for the development of potential therapeutics against the human coronavirus. Scutellarein, a natural product isolated from Scutellaria bacalensis, suppressed the activity of the SARS coronavirus helicase, nsP13, by controlling ATPase activity (Yu et al., 2012).

\section{ALKALOIDS}

\section{Cepharanthine}

Cepharanthine, a natural product isolated from the medicinal plant Stephania tetrandra, has been reported to exert antiviral effects against human hepatitis B virus, human immunodeficiency virus 1 (HIV 1), and human T-lymphotropic virus type 1 (Toyama et al., 2012; Zhou et al., 2012; Matsuda et al., 2014). Cepharanthine showed anti-inflammatory and antineoplastic effects and suppressed cell death provoked by human coronavirus-OC43 (HCoV-OC43) in the human pulmonary system. The molecule also mitigated viral $\mathrm{S}$ and $\mathrm{N}$ protein expressions, thereby decreasing the replication of the virus (Kim et al., 2019).

\section{Fangchinoline}

Fangchinoline, a natural product isolated from the medicinal plant Stephania tetrandra, has been reported to exert antiviral effects against HIV 1 (Wan et al., 2012). The molecule showed anti-inflammatory and antineoplastic effects. Fangchinoline suppressed cell death induced by HCoV-OC43 in the human pulmonary system. It also suppressed viral $\mathrm{S}$ and $\mathrm{N}$ protein expressions, thereby decreasing the replication of the virus (Kim et al., 2019).

\section{Homoharringtonine}

Homoharringtonine, a natural product, was shown to suppress the viral activities of the Newcastle disease virus, vesicular stomatitis virus, varicella-zoster virus, human echovirus 1 , and hepatitis B virus (Romero et al., 2007; Dong et al., 2018; Andersen et al., 2019; Kim and Song, 2019). In addition, homoharringtonine showed potent antiviral effects against various human coronaviruses. It suppressed infection by coronavirus by affecting viral replication. It has been reported to be an inhibitor of protein synthesis (Lü and Wang, 2014; Cao et al., 2015; Dong et al., 2018).

\section{Indigo}

Isatis indigotica, containing indigo as the major active constituent, is a medicinal plant empirically used in Asian medicine for controlling hepatitis, encephalitis, and influenza (Qin and Xu, 1998; Ho and Chang, 2002; Chang et al., 2012). Indigo was shown to inhibit the replication of the Japanese encephalitis virus, possibly by interfering with the attachment of the virus to its receptor (Chang et al., 2012). Furthermore, indigo was shown to suppress the activity of 3CLpro (Lin et al., 2005; Berry et al., 2015).

\section{Lycorine}

Lycorine, a natural product isolated from Lycoris radiata (Spider lily), showed anti-inflammatory and antiviral activities against a multitude of viruses, including SARS-CoV, by suppressing viral replication (Li et al., 2005; Cao et al., 2013; Zhang et al., 2020). This inhibition of viral RNA replication may have been a result of interfering with viral RNA translation. In addition, lycorine was reported to inhibit influenza virus nucleoprotein movement from the nucleus and downregulate autophagy (Liu et al., 2011; He et al., 2013; Wang et al., 2014, 2019).

\section{Oxysophoridine}

Oxysophoridine is a natural product isolated from Siphocampylus verticillatus and Sophora alopecuroides. This compound exerts a multitude of pharmacological effects, including antioxidative, antineoplastic, anti-apoptotic, and anti-inflammatory properties (Yang et al., 2012; Yao et al., 2012; Rui et al., 2013; Wang et al., 2015; Cao et al., 2018). An in vitro 
study showed that oxysophoridine might inhibit the replication of SARS-CoV-2 (Zhang et al., 2020). Owing to this, expedited investigations should be performed to determine the in vivo effect of this compound and elucidate its underlying molecular mechanism.

\section{Tryptanthrin}

Tryptanthrin is a major constituent isolated from the medicinal plant Strobilanthes cusia. This medicinal plant has been empirically used in Asian folk medicine to control infectious diseases including viral pneumonia, encephalitis, influenza, mumps, and cerebrospinal meningitis (Tanaka et al., 2004; Shahni and Handique, 2013; Gu et al., 2015; Lee et al., 2019). Tryptanthrin was shown to exert a potent antiviral effect on cells infected with HCoV-NL63 by affecting viral replication (Tsai et al., 2020).

\section{Tetrandrine}

Tetrandrine, a natural product isolated from the medicinal plant Stephania tetrandra, was reported to exert anti-inflammatory and antineoplastic effects (Kim et al., 2019). In human lung cells, tetrandrine prevented viral production following infection by the dengue virus (Liou et al., 2008). It also suppressed Ebola virus infection in human macrophages (Sakurai et al., 2015) and herpes simplex virus type 1 infection in ocular tissues (Hu et al., 1997). Furthermore, tetrandrine suppressed $\mathrm{HCoV}-\mathrm{OC} 43$-induced cell death in the human pulmonary system. The compound also mitigated viral $\mathrm{S}$ and $\mathrm{N}$ protein expressions, thereby decreasing the replication of the virus (Kim et al., 2019).

\section{Tylophorine}

Tylophorine, a natural product of Tylophora indica, was shown to exert anti-inflammatory effects in patients with hepatitis $C$ and inhibitory effects on the replication of the human hepatitis C virus (Raina and Raina, 1980; You et al., 2006; Yang et al., 2007; Pham et al., 2012; Wang et al., 2017). Tylophorine also suppresses the virulence of SARS-CoV by inhibiting viral replication and host cell apoptosis induced by the virus (Yang et al., 2010; Lee et al., 2012; Yang et al., 2017).

\section{OTHER GROUPS INCLUDING TRITERPENOIDS}

\section{Ascorbic acid}

Ascorbic acid has been reported to exert antidiabetic, immunomodulatory, antioxidative, and antifibrotic effects as well as protective effects against pulmonary infections. Clinical and non-clinical investigations have suggested ascorbic acid as potentially having ameliorating effects in patients with pneumonia, sepsis, idiopathic pulmonary fibrosis, acute respiratory distress syndrome, multiple organ failure, and acute lung injury. These symptoms have also been observed in patients with COVID-19 (Hunt et al., 1994; Nathens et al., 2002; Wintergerst et al., 2006; Chambial et al., 2013; Fisher et al., 2014; Bharara et al., 2016; Carr and Maggini, 2017; Hong et al., 2018; Rodrigues da Silva et al., 2018). Thus, ascorbic acid may be used in the management of clinical symptoms of COVID-19.

\section{Astragalosides}

Astragaloside IV, derived from Astragalus membranaceus, has been reported to exert anti-inflammatory effects by suppressing the production of nitric oxide and the release of proinflammatory cytokines (Qi et al., 2017). These biological activities of astragaloside IV suggest a potential for its use as an agent for managing cytokine storm, which is the main cause of mortality in COVID-19.

\section{Bananin}

Regulation of the SARS-CoV NTPase/helicase might be a potential strategy for the inhibition of SARS-CoV virulence. Bananin, a natural product, was shown to suppress the activities of ATPase and helicase of the SARS-CoV NTPase/helicase. Bananin has also been reported to suppress SARS-CoV replication in Frhk-4, a fetal rhesus monkey kidney cell line (De Clercq, 2006).

\section{Cinanserin}

Cinanserin is a natural product that suppresses the replication of SARS-CoV and is a potential inhibitor of SARS-CoV proteases. Binding of cinanserin to the active site of $3 \mathrm{CLpro}$ was shown to interrupt the processing of precursor polyproteins to the functional replicase which is required for viral replication (Chiow et al., 2016).

\section{Cinnamaldehyde}

Cinnamaldehyde, derived from Cinnamomi cortex, has been reported to exhibit anti-inflammatory, antiviral, and antioxidant activities (Jayaprakasha and Rao, 2011; Rao and Gan, 2014; Kawatra and Rajagopalan, 2015; Polansky and Lori, 2020). Cinnamomi cortex, which contains cinnamaldehyde as the major component, has been reported to mitigate the production of inflammatory markers such as IL-6 and TNF- $\alpha$. In addition, the molecule decreased the phosphorylation of ERK1/2, p38, and JNK, and suppressed the activa-

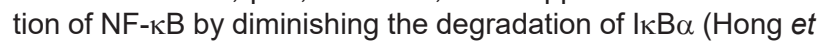
al., 2012). It was also postulated to possess inhibitory activity against proteolytic activation of spike protein in SARS-CoV-2 by proteases in host cells, since cinnamon was reported to be a trypsin inhibitor (Shahwar et al., 2012; Gopalakrishnan et al., 2018). All these investigations implicate a potential therapeutic role of cinnamaldehyde as an agent for managing SARSCoV-2 infection.

\section{Curcumin}

Curcumin, a well-known bioactive component of turmeric, has been reported to exert immunomodulatory, antioxidative, antifibrotic, and anti-inflammatory effects by controlling JNK as well as signal transducers and activators of the transcription (STAT) signaling pathway (Menon and Sudheer, 2007; Jurenka, 2009; Srivastava et al., 2011; Kocaadam and Şanlier, 2017). It has also been reported to ameliorate oxidative stress, pulmonary fibrosis, and inflammation in animal models of pulmonary fibrosis induced by chemicals, viruses, and radiation (Punithavathi et al., 2000; Lee et al., 2010; Hügle, 2011; Avasarala et al., 2013; Chen et al., 2017; Zahedipour et al., 2020). Curcumin was reported to modulate the function of natural killer cells, dendritic cells, T cells, neutrophils, B cells, and macrophages (Gautam et al., 2007). In this context, curcumin might show potential activities, including protection against acute lung injury, pulmonary fibrosis, and acute respiratory distress syndrome, as well as improving the overall function of the lungs. These are the optimal activities required 
for the regulation of clinical symptoms observed in patients with COVID-19.

\section{Diallyl thiosulfonate}

Allium sativum containing diallyl thiosulfonate, alliin, and S-allyl cysteine as the major active components has been reported to exert therapeutic effects by controlling edema of the alveolar inner region, pulmonary fibrosis, respiratory tract infections, acute lung injury, and sepsis. Diallyl thiosulfonate and other components of Allium sativum showed antioxidative, antiviral, immunomodulatory, anti-inflammatory, and antifibrotic effects (Bayan et al., 2014; Arreola et al., 2015; Shang et al., 2019). These results implied that diallyl thiosulfonate and other phytochemicals in Allium sativum might be used to regulate the symptoms seen in patients with COVID-19.

\section{Emodin}

Emodin has been reported to suppress the interaction between SARS-CoV spike protein and the angiotensin-converting enzyme 2 of the host. It also suppresses the function of the 3a ion channel of SARS-CoV. This suppression is thought to interfere with the release of the virus from infected cells ( $\mathrm{Ho}$ et al., 2007; Schwarz et al., 2011).

\section{Glycyrrhizin}

Glycyrrhizin, an active component isolated from Glycyrrhizae radix, has been reported to suppress the replication of SARS-CoV (Yang et al., 2020). In addition, glycyrrhizin was reported to inhibit the replication, adsorption, and penetration of coronavirus (Cinatl et al., 2003; Fiore et al., 2008).

\section{Nimbolide}

Nimbolide, isolated from the medicinal plant Azadirachta indica, has been reported to exert antifibrotic activity in lung tissue, including reduction of biological markers of fibrosis and oxidative stress, through the suppression of the TGF- $\beta$ / Smad intracellular signaling pathway (Prashanth Goud et al., 2019). These biological activities of nimbolide suggest its potential use as an agent to manage lung injury and pulmonary fibrosis, all of which are symptoms that occur in patients with COVID-19.

\section{Piperine}

Piperine, a bioactive compound derived from Piper nigrum, has been reported to exert anti-inflammatory, antiviral, and antioxidant activities (Vijayakumar et al., 2004; Butt et al., 2013). Piperine showed an effect of enhancing the bioavailability of an agent administered simultaneously with it by increasing the gastrointestinal absorption of that agent (Pattanaik et al., 2009). Therefore, piperine might be developed as a potentiator of orally administered agents aimed at treating or managing COVID-19.

\section{Saikosaponins}

Saikosaponins derived from an anti-inflammatory medicinal plant, Bupleurum falcatum, showed a multitude of biological activities, including immunomodulation, anti-hepatitis activity, anti-bacterial effects, and activity against nephritis. It has been reported that saikosaponin B2 exerted an antiviral effect by inhibiting the penetration and attachment of HCoV-229E (Cheng et al., 2006).

\section{CONCLUSIONS AND FUTURE PERSPECTIVES}

After the outbreak of COVID-19, biomedical scientists worldwide have been investigating the development of novel therapeutics and safe and efficacious vaccines to mitigate the spread of the virus and retard the morbidity and mortality of COVID-19. Although several vaccines for COVID-19 manufactured by pharmaceutical companies are currently being used in clinics worldwide, the COVID-19 pandemic has not been effectively controlled, as there are various hurdles in rapid immunization drives, including the difficulties in mass production and the swift distribution of adequate doses to all populations globally. Therefore, novel therapeutic agents, preferably for oral administration, which can eradicate the core cause of the disease, and/or manage the clinical symptoms of COVID-19 should be developed to effectively regulate this global pandemic. As presented in this review, we attempted to postulate and scientifically rationalize the possibility of managing the clinical symptoms of COVID-19 using natural products derived from medicinal plants used for controlling pulmonary inflammatory diseases in folk medicine. Diverse natural products have been reported to exert potential antiviral effects in vitro by affecting viral replication, viral entry into host cells, viral assembly in host cells, and viral release. However, the in vivo antiviral effects and clinical antiviral efficacies of these natural products against SARS-CoV-2 have not been successfully proven do date. Thus, these properties should be further elucidated through investigations, including randomized clinical trials, in order to develop optimal and ideal therapeutic candidates for COVID-19.

\section{CONFLICT OF INTEREST}

The authors declare that they have no conflicts of interest.

\section{ACKNOWLEDGMENTS}

This research was supported by NRF-2014R1A6A1029617, Basic Science Research Program through the National Research Foundation of Korea (NRF) funded by the Ministry of Education.

\section{REFERENCES}

Al-Bari, M. A. A. (2017) Targeting endosomal acidification by chloroquine analogs as a promising strategy for the treatment of emerging viral diseases. Pharmacol. Res. Perspect. 5, e00293.

Andersen, P. I., Krpina, K., lanevski, A., Shtaida, N., Jo, E., Yang, J., Koit, S., Tenson, T., Hukkanen, V., Anthonsen, M. W., Bjoras, M., Evander, M., Winaisch, M. P., Zusinaite, E. and Kainov, D. E. (2019) Novel antiviral activities of obatoclax, emetine, niclosamide, brequinar, and homoharringtonine. Viruses 11, 964.

Arreola, R., Quintero-Fabián, S., López-Roa, R. I., Flores-Gutiérrez, E. O., Reyes-Grajeda, J. P., Carrera-Quintanar, L. and Ortuño-Sahagún, D. (2015) Immunomodulation and anti-inflammatory effects of garlic compounds. J. Immunol. Res. 2015, 401630.

Avasarala, S., Zhang, F., Liu, G., Wang, R., London, S. D. and London, L. (2013) Curcumin modulates the inflammatory response and inhibits subsequent fibrosis in a mouse model of viral-induced acute respiratory distress syndrome. PLOS ONE 8, e57285.

Baracco, G. J. (2021) Remdesivir use and hospital length of stay-the 
paradox of a clinical trial vs real-life use. JAMA Netw. Open 4, e2116057.

Bartoletti, M., Marconi, L., Scudeller, L., Pancaldi, L., Tedeschi, S., Giannella, M., Rinaldi, M., Bussini, L., Valentini, I., Ferravante, A. F., Potalivo, A., Marchionni, E., Fornaro, G., Pascale, R., Pasquini, Z., Puoti, M., Merli, M., Barchiesi, F., Volpato, F., Rubin, A., Saracino, A., Tonetti, T., Gaibani, O., Ranieri, V. M., Viale, P. and Cristini, F.; PREDICO Study Group (2021) Efficacy of corticosteroid treatment for hospitalized patients with severe COVID-19: a multicentre study. Clin. Microbiol. Infect. 27, 105-111.

Bayan, L., Koulivand, P. H. and Gorji, A. (2014) Garlic: a review of potential therapeutic effects. Avicenna J. Phytomed. 4, 1-14.

Berry, M., Fielding, B. and Gamieldien, J. (2015) Potential broad spectrum inhibitors of the coronavirus 3CLpro: a virtual screening and structure-based drug design study. Viruses 7, 6642-6660.

Bharara, A., Grossman, C., Grinnan, D., Syed, A., Fisher, B., DeWilde, C., Natrajan, R. and Fowler, A. A. (2016) Intravenous vitamin C administered as adjunctive therapy for recurrent acute respiratory distress syndrome. Case Rep. Crit. Care 2016, 8560871.

Breining, P., Frølund, A. L., Højen, J. F., Gunst, J. D., Staerke, N. B., Saedder, E., Cases-Thomas, M., Little, P., Nielsen, L. P., Søgaard, O. S. and Kjolby, M. (2021) Camostat mesylate against SARSCoV-2 and COVID-19-rationale, dosing and safety. Basic Clin. Pharmacol. Toxicol. 128, 204-212.

Butt, M. S., Pasha, I., Sultan, M. T., Randhawa, M. A., Saeed, F. and Ahmed, W. (2013) Black pepper and health claims: a comprehensive treatise. Crit. Rev. Food Sci. Nutr. 53, 875-886.

Cao, J., Forrest, J. C. and Zhang, X. A. (2015) A screen of the NIH clinical collection small molecule library identifies potential anticoronavirus drugs. Antiviral Res. 114, 1-10.

Cao, Z., Chen, L., Liu, Y. and Peng, T. (2018) Oxysophoridine rescues spinal cord injury via anti-inflammatory, anti-oxidative stress and anti-apoptosis effects. Mol. Med. Rep. 17, 2523-2528.

Cao, Z., Yang, P. and Zhou, Q. (2013) Multiple biological functions and pharmacological effects of lycorine. Sci. China Chem. 56, 13821391.

Carr, A. C. and Maggini, S. (2017) Vitamin C and immune function. Nutrients 9, 1211

Chambial, S., Dwivedi, S., Shukla, K. K., John, P. J. and Sharma, P. (2013) Vitamin C in disease prevention and cure: an overview. Indian J. Clin. Biochem. 28, 314-328.

Chang, S. J., Chang, Y. C., Lu, K. Z., Tsou, Y. Y. and Lin, C. W. (2012) Antiviral activity of isatis indigotica extract and its derived indirubin against Japanese encephalitis virus. Evid. Based Complement. Alternat. Med. 2012, 925830.

Chen, C. J., Michaelis, M., Hsu, H. K., Tsai, C. C., Yang, K. D., Wu, Y. C., Cinatl, J., Jr. and Doerr, H. S. (2008) Toona sinensis Roem tender leaf extract inhibits SARS coronavirus replication. J. Ethnopharmacol. 120, 108-111.

Chen, H., Yang, R., Tang, Y., Xu, J., Feng, Y., Liu, S., Zhang, S. and Hou, L. (2017) Effects of curcumin on pulmonary fibrosis and functions of paraquat-challenged rats. Zhonghua Wei Zhong Bing Ji Jiu Yi Xue 29, 973-976.

Chen, L. and Zhao, W. (2016) Apigenin protects against bleomycininduced lung fibrosis in rats. Exp. Ther. Med. 11, 230-234.

Chen, Z. and Nakamura, T. (2004) Statistical evidence for the usefulness of Chinese medicine in the treatment of SARS. Phytother. Res. 18, 592-594.

Cheng, P. W., Ng, L. T., Chiang, L. C. and Lin, C. C. (2006) Antiviral effects of saikosaponins on human coronavirus 229E in vitro. Clin. Exp. Pharmacol. Physiol. 33, 612-616.

Chiow, K. H., Phoon, M. C., Putti, T., Tan, B. K. H. and Chow, V. T. (2016) Evaluation of antiviral activities of houttuynia cordata Thunb. extract, quercetin, quercetrin and cinanserin on murine coronavirus and dengue virus infection. Asian Pac. J. Trop. Med. 9, 1-7.

Chu, C. M., Cheng, V. C., Hung, I. F., Wong, M. M., Chan, K. H., Chan, K. S., Kao, R. Y., Poon, L. L., Wong, C. L., Guan, Y., Peiris, K. S. and Yuen, K. Y.; HKU/UCH SARS Study Group (2004) Role of lopinavir/ritonavir in the treatment of SARS: initial virological and clinical findings. Thorax 59, 252-256.

Cinatl, J., Morgenstern, B., Bauer, G., Chandra, P., Rabenau, H. and Doerr, H. W. (2003) Glycyrrhizin, an active component of liquorice roots, and replication of SARS-associated coronavirus. Lancet 361, 2045-2046.

De Clercq, E. (2006) Potential antivirals and antiviral strategies against SARS coronavirus infections. Expert Rev. Anti Infect. Ther. 4, 291302.

de Wilde, A. H., Zevenhoven-Dobbe, J. C., van der Meer, Y., Thiel, V., Narayanan, K., Makino, S., Snijder, E. J. and van Hemert, M. J. (2011) Cyclosporin A inhibits the replication of diverse coronaviruses. J. Gen. Virol. 92, 2542-2548.

Deng, Y. F., Aluko, R. E., Jin, Q., Zhang, Y. and Yuan, L. J. (2012) Inhibitory activities of baicalin against renin and angiotensin-converting enzyme. Pharm. Biol. 50, 401-406.

Dong, H. J., Wang, Z. H., Meng, W., Li, C. C., Hu, Y. X., Zhou, L. and Wang, X. J. (2018) The natural compound homoharringtonine presents broad antiviral activity in vitro and in vivo. Viruses 10,601.

Farazuddin, M., Mishra, R., Jing, Y., Srivastava, V., Comstock, A. T. and Sajjan, U. S. (2018) Quercetin prevents rhinovirus-induced progression of lung disease in mice with COPD phenotype. PLOS ONE 13, e0199612.

Fardet, L. and Fève, B. (2014) Systemic glucocorticoid therapy: a review of its metabolic and cardiovascular adverse events. Drugs 74, 1731-1745.

Fiore, C., Eisenhut, M., Krausse, R., Ragazzi, E., Pellati, D., Armanini, D. and Bielenberg, J. (2008) Antiviral effects of Glycyrrhiza species. Phytother. Res. 22, 141-148.

Fisher, B. J., Kraskauskas, D., Martin, E. J., Farkas, D., Puri, P., Massey, H. D., Idowu, M. O., Brophy, D. F., Voelkel, N. F., Fowler, A. A., 3rd and Natarajan, R. (2014) Attenuation of sepsis-induced organ injury in mice by vitamin C. J. Parenter. Enter. Nutr. 38, 825839.

Foolad, F., Aitken, S. L., Shigle, T. L., Prayag, A., Ghantoji, S., ArizaHeredia, E. and Chemaly, R. F. (2019) Oral versus aerosolized ribavirin for the treatment of respiratory syncytial virus infections in hematopoietic cell transplant recipients. Clin. Infect. Dis. 68, 16411649.

Gautam, S. C., Gao, X. and Dulchavsky, S. (2007) Immunomodulation by curcumin. Adv. Exp. Med. Biol. 595, 321-341.

Goletti, D. and Cantini, F. (2021) Baricitinib therapy in covid-19 pneumonia - an unmet need fulfilled. N. Engl. J. Med. 384, 867-869.

Gopalakrishnan, S., Ediga, H. H., Reddy, S. S., Reddy, G. B. and Ismail, A. (2018) Procyanidin-B2 enriched fraction of cinnamon acts as a proteasome inhibitor and anti-proliferative agent in human prostate cancer cells. IUBMB Life 70, 445-457.

Gu, W., Wang, W., Li, X., Zhang, Y., Wang, L., Yuan, C., Huang, L. and Hao, X. (2015) A novel isocoumarin with anti-influenza virus activity from strobilanthes cusia. Fitoterapia 107, 60-62.

Gustine, J. N. and Jones, D. (2021) Immunopathology of hyperinflammation in COVID-19. Am. J. Pathol. 191, 4-17.

Gumel, A. B., Iboi, E. A., Ngonghala, C. N. and Ngwa, G. A. (2021) Toward achieving a vaccine-derived herd immunity threshold for COVID-19 in the U.S. Front. Public Health 9, 709369.

He, J., Qi, W. B., Wang, L., Tian, J., Jiao, P. R., Liu, G. Q., Ye, W. C. and Liao, M. (2013) Amaryllidaceae alkaloids inhibit nuclear-tocytoplasmic export of ribonucleoprotein (RNP) complex of highly pathogenic avian influenza virus H5N1. Influenza Other Respir. Viruses 7, 922-931.

Ho, T., Wu, S., Chen, J., Li, C. and Hsiang, C. (2007) Emodin blocks the SARS coronavirus spike protein and angiotensin-converting enzyme 2 interaction. Antiviral Res. 74, 92-101.

Ho, Y. L. and Chang, Y. S. (2002) Studies on the antinociceptive, antiinflammatory and anti pyretic effects of Isatis indigotica root. Phytomedicine 9, 419-424.

Hoffmann, M., Schroeder, S., Kleine-Weber, H., Müller, M. A., Drosten, C. and Pöhlmann, S. (2020) Nafamostat mesylate blocks activation of SARS-CoV-2: new treatment option for COVID-19. Antimicrob. Agents Chemother. 64, e00754-20.

Hong, J. W., Yang, G. E., Kim, Y. B., Eom, S. H., Lew, J. H. and Kang, H. (2012) Anti-inflammatory activity of cinnamon water extract in vivo and in vitro LPS-induced models. BMC Complement. Altern. Med. 12, 237.

Hong, J. Y., Lee, C. Y., Lee, M. G. and Kim, Y. S. (2018) Effects of dietary antioxidant vitamins on lung functions according to gender 
and smoking status in Korea: a population-based cross-sectional study. BMJ Open 8, e020656.

Hu, S., Dutt, J., Zhao, T. and Foster, C. S. (1997) Tetrandrine potently inhibits herpes simplex virus type-1-induced keratitis in BALB/C mice. Ocul. Immunol. Inflamm. 5, 173-180.

Hu, Z., Lv, Y., Xu, C., Sun, W., Chen, W., Peng, Z., Chen, C., Cui, X., Jiao, D., Cheng, C., Chi, Y., Wei, H., Hu, C., Zeng, Y., Zhang, X. and Yi, Y. (2020) Clinical use of short-course and low-dose corticosteroids in patients with non-severe COVID-19 during pneumonia progression. Front. Public Health 8, 355.

Hügle, T. (2011) Immunology of fibrotic lung disease: managing infections whilst preventing autoimmunity? J. Inflamm. Res. 4, 21-27.

Hunt, C., Chakravorty, N. K., Annan, G., Habibzadeh, N. and Schorah, C. J. (1994) The clinical effects of vitamin C supplementation in elderly hospitalised patients with acute respiratory infections. Int J. Vitam. Nutr. Res. 64, 212-219.

Jang, W. D., Jeon, S., Kim, S. and Lee, S. Y. (2021) Drugs repurposed for COVID-19 by virtual screening of 6,218 drugs and cell-based assay. Proc. Natl. Acad. Sci. U.S.A. 118, e2024302118.

Jayaprakasha, G. K. and Rao, L. J. M. (2011) Chemistry, biogenesis, and biological activities of cinnamomum zeylanicum. Crit. Rev. Food Sci. Nutr. 51, 547-562.

Jo, S., Kim, S., Shin, D. H. and Kim, M. S. (2020) Inhibition of SARSCoV 3CL protease by flavonoids. J. Enzyme Inhib. Med. Chem. 35, 145-151.

Jurenka, J. S. (2009) Anti-inflammatory properties of curcumin, a major constituent of curcuma longa: a review of preclinical and clinical research. Altern. Med. Rev. 14, 141-153.

Kadam, R. U. and Wilson, I. A. (2017) Structural basis of influenza virus fusion inhibition by the antiviral drug Arbidol. Proc. Natl. Acad. Sci. U.S.A. 114, 206-214.

Kawatra, P. and Rajagopalan, R. (2015) Cinnamon: mystic powers of a minute ingredient. Pharmacogn. Res. 7, S1-S6.

Khamitov, R. A., Loginova, S., Shchukina, V. N., Borisevich, S. V., Maksimov, V. A. and Shuster, A. M. (2008) Antiviral activity of arbidol and its derivatives against the pathogen of severe acute respiratory syndrome in the cell cultures. Vopr. Virusol. 53, 9-13.

Kim, D., Min, J., Jang, M., Lee, J., Shin, Y., Park, C., Song, J., Kim, H., Kim, S., Jin, Y. H. and Kwon, S. (2019) Natural bis-benzylisoquinoline alkaloids-tetrandrine, fangchinoline, and cepharanthine, inhibit human Coronavirus OC43 infection of MRC-5 human lung cells. Biomolecules 9, 696 .

Kim, J. E. and Song, Y. J. (2019) Anti-varicella-zoster virus activity of cephalotaxine esters in vitro. J. Microbiol. 57, 74-79.

Kocaadam, B. and Şanlier, N. (2017) Curcumin, an active component of turmeric (Curcuma longa), and its effects on health. Crit. Rev. Food Sci. Nutr. 57, 2889-2895.

Krishna, S., Augustin, Y., Wang, J., Xu, C., Staines, H. M., Platteeuw, H., Kamarulzaman, A., Sall, A. and Kremsner, P. (2021) Repurposing antimalarials to tackle the COVID-19 pandemic. Trends Parasitol. 37, 8-11.

Kumar, S. and Pandey, A. K. (2013) Chemistry and biological activities of flavonoids: an overview. ScientificWorldJournal 2013, 162750.

La Rosée, F., Bremer, H. C., Gehrke, I., Kehr, A., Hochhaus, A., Birndt, S., Fellhauer, M., Henkes, M., Kumle, B., Russo, S. G. and La Rosée, P. (2020) The Janus kinase 1/2 inhibitor ruxolitinib in COVID-19 with severe systemic hyperinflammation. Leukemia 34, 1805-1815.

Lee, C. L., Wang, C. M., Hu, H. C., Yen, H. R., Song, Y. C., Yu, S. J., Chen, C. J., Li, W. C. and Wu, Y. C. (2019) Indole alkaloids indigodoles A-C from aerial parts of strobilanthes cusia in the traditional Chinese medicine qing dai have anti-IL-17 properties. Phytochemistry 162, 39-46.

Lee, J. C., Kinniry, P. A., Arguiri, E., Serota, M., Kanterakis, S., Chatterjee, S., Solomides, C. C., Javvadi, P., Coumenis., C., Cengel, K. A. and Christofidou-Solomidou, M. (2010) Dietary curcumin increases antioxidant defenses in lung, ameliorates radiation-induced pulmonary fibrosis, and improves survival in mice. Radiat. Res. 173, 590-601.

Lee, Y. Z., Yang, C. W., Hsu, H. Y., Qiu, Y. Q., Yeh, T. K., Chang, H. Y., Chao, Y. S. and Lee, S. J. (2012) Synthesis and biological evaluation of tylophorine-derived dibenzoquinolines as orally active agents: exploration of the role of tylophorine $E$ ring on biological activity. J. Med. Chem. 55, 10363-10377.

Li, G. and De Clercq, E. (2020) Therapeutic options for the 2019 novel coronavirus (2019-nCoV). Nat. Rev. Drug Discov. 19, 149-150.

Li, S., Chen, C., Zhang, H., Guo, H., Wang, H., Wang, L., Zhang, X., Hua, S., Yu, J., Xiao, P., Li, R. S. and Tan, X. (2005) Identification of natural compounds with antiviral activities against SARS-associated coronavirus. Antiviral Res. 67, 18-23.

Lin, C. W., Tsai, F. J., Tsai, C. H., Lai, C. C., Wan, L., Ho, T. Y., Hsieh, C. C. and Chao, P. D. L. (2005) Anti-SARS coronavirus 3C-like protease effects of Isatis indigotica root and plant-derived phenolic compounds. Antiviral Res. 68, 36-42.

Liou, J. T., Chen, Z. Y., Ho, L. J., Yang, S. P., Chang, D. M., Liang, C. C. and Lai, J. H. (2008) Differential effects of triptolide and tetrandrine on activation of $\mathrm{COX}-2, \mathrm{NF}-\kappa \mathrm{B}$, and $\mathrm{AP}-1$ and virus production in dengue virus-infected human lung cells. Eur. J. Pharmacol. 589, 288-298.

Liu, J., Yang, Y., Xu, Y., Ma, C., Qin, C. and Zhang, L. (2011) Lycorine reduces mortality of human enterovirus 71 -infected mice by inhibiting virus replication. Virol. J. 8, 483.

Lü, S. and Wang, J. (2014) Homoharringtonine and omacetaxine for myeloid hematological malignancies. J. Hematol. Oncol. 7, 2.

Marefati, N., Eftekhar, N., Kaveh, M., Boskabadi, J., Beheshti, F. and Boskabady, M. H. (2018) The effect of Allium cepa extract on lung oxidant, antioxidant, and immunological biomarkers in ovalbuminsensitized rats. Med. Princ. Pract. 27, 122-128.

Matsuda, K., Hattori, S., Komizu, Y., Kariya, R., Ueoka, R. and Okada, S. (2014) Cepharanthine inhibited HIV-1 cell-cell transmission and cell-free infection via modification of cell membrane fluidity. Bioorg. Med. Chem. Lett. 24, 2115-2117.

Menon, V. P. and Sudheer, A. R. (2007) Antioxidant and anti-inflammatory properties of curcumin. Adv. Exp. Med. Biol. 595, 105-125.

Mentré, F., Taburet, J. M., Guedj, J., Anglaret, X., Keïta, S., de Lamballerie, X. and Malvy, D. (2015) Dose regimen of favipiravir for Ebola virus disease. Lancet Infect. Dis. 15, 150-151.

Nathens, A. B., Neff, M. J., Jurkovich, G. J., Klotz, P., Farver, K., Ruzinski, J. T., Radella, F., Garcia, I. and Maier, R. V. (2002) Randomized, prospective trial of antioxidant supplementation in critically ill surgical patients. Ann. Surg. 236, 814-822.

Ni, Y. N., Chen, G., Sun, J., Liang, B. M. and Liang, Z. A. (2019) The effect of corticosteroids on mortality of patients with influenza pneumonia: a systematic review and meta-analysis. Crit. Care 23, 99.

Park, J. Y., Ko, J. A., Kim, D. W., Kim, Y. M., Kwon, H. J., Jeong, H. J., Kim, C. Y., Park, K. H., Lee, W. S. and Ryu, Y. B. (2016) Chalcones isolated from Angelica keiskei inhibit cysteine proteases of SARSCoV. J. Enzyme Inhib. Med. Chem. 31, 23-30.

Pattanaik, D. S., Hota, D., Prabhakar, P. and Pandhi, P. (2009) Effect of simultaneous administration of piperine on plasma concentration of carbamazepine. Phytother. Res. 12, 264-269.

Pham, L. V., Ngo, H. T. T., Lim, Y. S. and Hwang, S. B. (2012) Hepatitis $C$ virus non-structural $5 B$ protein interacts with cyclin $A 2$ and regulates viral propagation. J. Hepatol. 57, 960-966.

Polansky, H. and Lori, G. (2020) Coronavirus disease 2019 (COVID-19): first indication of efficacy of Gene-Eden-VIR/Novirin in SARS-CoV-2 infection. Int. J. Antimicrob. Agents 55, 105971.

Prashanth Goud, M., Bale, S., Pulivendala, G., and Godugu, C. (2019) Therapeutic effects of Nimbolide, an autophagy regulator, in ameliorating pulmonary fibrosis through attenuation of TGF- $\beta 1$ driven epithelial-to-mesenchymal transition. Int. Immunopharmacol. 75, 105755.

Punithavathi, D., Venkatesan, N. and Babu, M. (2000) Curcumin inhibition of bleomycin-induced pulmonary fibrosis in rats. $\mathrm{Br}$. J. Pharmacol. 131, 169-172.

Qi, Y., Gao, F., Hou, L. and Wan, C. (2017) Anti-inflammatory and immunostimulatory activities of astragalosides. Am. J. Chin. Med. 45, 1157-1167.

Qin, G. W. and Xu, R. S. (1998) Recent advances on bioactive natural products from Chinese medicinal plants. Med. Res. Rev. 18, 375382.

Raina, V. and Raina, S. (1980) The responsiveness of leukocyte adenyl cyclase to tylophorine in asthmatic subjects. Biochem. Biophys. Res. Commun. 94, 1074-1077. 
Rao, P. V. and Gan, S. H. (2014) Cinnamon: a multifaceted medicinal plant. Evid. Based Complement. Alternat. Med. 2014, 642942.

Rodrigues da Silva, M., Schapochnik, A., Peres Leal, M., Esteves, J., Bichels Hebeda, C., Sandri, S., Pavani, C., Ratto Tempestini Horliana, A. C., Farsky, S. H. P. and Lino-dos-Santos-Franco, A. (2018) Beneficial effects of ascorbic acid to treat lung fibrosis induced by paraquat. PLoS ONE 13, e0205535.

Romero, M., Serrano, M., Efferth, T., Alvarez, M. and Marin, J. (2007) Effect of cantharidin, cephalotaxine and homoharringtonine on "in vitro" models of hepatitis b virus (HBV) and bovine viral diarrhoea virus (BVDV) replication. Planta Med. 73, 552-558.

Rossignol, J. F. (2016) Nitazoxanide, a new drug candidate for the treatment of middle east respiratory syndrome coronavirus. J. Infect. Public Health 9, 227-230.

Rui, C., Yuxiang, L., Ning, J., Ningtian, M., Qingluan, Z., Yinju, H., Ru, Z., Lin, M., Tao, S. and Jianqiang, Y. (2013) Anti-apoptotic and neuroprotective effects of oxysophoridine on cerebral ischemia both in vivo and in vitro. Planta Med. 79, 916-923.

Sakurai, Y., Kolokoltsov, A. A., Chen, C. C., Tidwell, M. W., Bauta, W. E., Klugbauer, N., Grimm, C., Wahl-Schott, C., Biel, M. and Davey, R. A. (2015) Two-pore channels control Ebola virus host cell entry and are drug targets for disease treatment. Science 347, 995-998.

Savarino, A., Boelaert, J. R., Cassone, A., Majori, G. and Cauda, R. (2003) Effects of chloroquine on viral infections: an old drug against today's diseases? Lancet Infect. Dis. 3, 722-727.

Schwarz, S., Sauter, D., Wang, K., Zhang, R., Sun, B., Karioti, A., Billa, A. R., Efferth, T. and Schwarz, W. (2014) Kaempferol derivatives as antiviral drugs against the $3 a$ channel protein of coronavirus. Planta Med. 80, 177-182.

Schwarz, S., Wang, K., Yu, W. J., Sun, B. and Schwarz, W. (2011) Emodin inhibits current through SARS-associated coronavirus $3 a$ protein. Antiviral Res. 90, 64-69.

Shahabi, R., Anissian, A., Javadmoosavi, S. A. and Nasirinezhad, F. (2019) Protective and anti-inflammatory effect of selenium nanoparticles against bleomycin-induced pulmonary injury in male rats. Drug Chem. Toxicol. 44, 92-100.

Shahni, R. and Handique, P. J. (2013) Antibacterial properties of leaf extracts of strobilanthes cusia (Nees) kuntze, a rare ethno-medicinal plant of manipur, India. Int. J. Pharm. Tech. Res. 5, 1281-1285.

Shahwar, D., Raza, M. A., Shafiq-Ur-Rehman, Abbasi, M. A. and AttaUr-Rahman. (2012) An investigation of phenolic compounds from plant sources as trypsin inhibitors. Nat. Prod. Res. 26, 1087-1093.

Shang, A., Cao, S. Y., Xu, X. Y., Gan, R. Y., Tang, G. Y., Corke, H., Mavumengwana, V. and Li, H. B. (2019) Bioactive compounds and biological functions of garlic (Allium sativum L.). Foods 8, 246.

Siegel, D., Hui, H. C., Doerffler, E., Clarke, M. O., Chun, K., Zhang, L., Neville, S., Carra, E., Lew, W., Ross, B., Wang, Q., Wolfe, L., Jordan, R., Soloveva, V., Knox, J., Perry, J., Perron, M., Stray, K. M., Barauskas, O., Feng, J. Y., Xu, Y., Lee, G., Rheingold, A. L., Ray, A. S., Bannister, R., Strickley, R., Swaminathan, S., Lee, W. A., Bavari, S., Cihlar, T., Lo, M. K., Warren, T. K. and Mackman, R. L. (2017) Discovery and synthesis of a phosphoramidate prodrug of a pyrrolo[2,1-f][triazin-4-amino] adenine c-nucleoside (GS-5734) for the treatment of Ebola and emerging viruses. J. Med. Chem. 60, 1648-1661.

Srivastava, R. M., Singh, S., Dubey, S. K., Misra, K. and Khar, A. (2011) Immunomodulatory and therapeutic activity of curcumin. Int. Immunopharmacol. 11, 331-341.

Suleria, H. A. R., Butt, M. S., Anjum, F. M., Saeed, F. and Khalid, N. (2015) Onion: nature protection against physiological threats. Crit. Rev. Food Sci. Nutr. 55, 50-66.

Tanaka, T., Ikeda, T., Kaku, M., Zhu, X. H., Okawa, M., Yokomizo, K., Uyeda, M. and Nohara, T. (2004) A new lignan glycoside and phenylethanoid Glycosides from strobilanthes cusia BREMEK. Chem. Pharm. Bull. 52, 1242-1245.

Toyama, M., Hamasaki, T., Uto, T., Aoyama, H., Okamoto, M., Hashmoto, Y. and Baba, M. (2012) Synergistic inhibition of HTLV-1-infected cell proliferation by combination of cepharanthine and a tetramethylnaphthalene derivative. Anticancer Res. 32, 2639-2645.

Tsai, Y. C., Lee, C. L., Yen, H. R., Chang, Y. S., Lin, Y. P., Huang, S. H. and Lin, C. W. (2020) Antiviral action of tryptanthrin isolated from strobilanthes cusia leaf against human coronavirus NL63. Biomol- ecules 10, 366.

Vijayakumar, R. S., Surya, D. and Nalini, N. (2004) Antioxidant efficacy of black pepper (Piper nigrum L.) and piperine in rats with high fat diet induced oxidative stress. Redox Rep. 9, 105-110.

Wan, Z., Lu, Y., Liao, Q., Wu, Y. and Chen, X. (2012) Fangchinoline inhibits human immunodeficiency virus type 1 replication by interfering with gp160 proteolytic processing. PLoS ONE 7, e39225.

Wang, H., Guo, T., Yang, Y., Yu, L., Pan, X. and Li, Y. (2019) Lycorine derivative LY-55 inhibits EV71 and CVA16 replication through downregulating autophagy. Front. Cell. Infect. Microbiol. 9, 277.

Wang, P., Li, L. F., Wang, Q. Y., Shang, L. Q., Shi, P. Y. and Yin, Z. (2014) Anti-dengue-virus activity and structure-activity relationship studies of lycorine derivatives. ChemMedChem 9, 1522-1533.

Wang, Y. S., Li, Y. X., Zhao, P., Wang, H. B., Zhou, R., Hao, Y. J., Wang, J., Wang, S. J., Du, J., Ma, L., Sun, T. and Yu, J. Q. (2015) Anti-inflammation effects of oxysophoridine on cerebral ischemiareperfusion injury in mice. Inflammation 38, 2259-2268.

Wang, Y., Lee, S., Ha, Y., Lam, W., Chen, S. R., Dutschman, G. E., Gullen, E. A., Grill, S. P., Cheng, Y., Fürstner, A., Francis, S., Baker, D. C., Yang, X., Lee, K. H. and Cheng, Y. C. (2017) Tylophorine analogs allosterically regulates heat shock cognate protein 70 and inhibits hepatitis C virus replication. Sci. Rep. 7, 10037.

Wintergerst, E. S., Maggini, S. and Hornig, D. H. (2006) Immune-enhancing role of vitamin $\mathrm{C}$ and zinc and effect on clinical conditions. Ann. Nutr. Metab. 50, 85-94.

Xu, X., Han, M., Li, T., Sun, W., Wang, D., Fu, B., Zhou, Y., Zheng, X., Yang, Y., Li, X., Zhang, X., Pan, A. and Wei, H. (2020) Effective treatment of severe COVID-19 patients with tocilizumab. Proc. Natl. Acad. Sci. U.S.A. 117, 10970-10975.

Yang, C. W., Chuang, T. H., Wu, P. L., Huang, W. H. and Lee, S. J. (2007) Anti-inflammatory effects of 7-methoxycryptopleurine and structure-activity relations of phenanthroindolizidines and phenanthroquinolizidines. Biochem. Biophys. Res. Commun. 354, 942948.

Yang, C. W., Lee, Y. Z., Hsu, H. Y., Shih, C., Chao, Y. S., Chang, H. Y. and Lee, S. J. (2017) Targeting coronaviral replication and cellular JAK2 mediated dominant NF-kB activation for comprehensive and ultimate inhibition of Coronaviral activity. Sci. Rep. 7, 4105.

Yang, C. W., Lee, Y. Z., Kang, I. J., Barnard, D. L., Jan, J. T., Lin, D., Huang, C. W., Yeh, T. K., Chao, Y. S. and Lee, S. J. (2010) Identification of phenanthroindolizines and phenanthroquinolizidines as novel potent anti-coronaviral agents for porcine enteropathogenic coronavirus transmissible gastroenteritis virus and human severe acute respiratory syndrome coronavirus. Antiviral Res. 88, 160168.

Yang, G., Gao, J., Jia, Y., Yan, L., Yu, J. and Jiang, Y. (2012) Oxysophoridine through intrathecal injection induces antinociception and increases the expression of the GABAA 1 receptor in the spinal cord of mice. Planta Med. 78, 874-880.

Yang, Y., Islam, M. S., Wang, J., Li, Y. and Chen, X. (2020) Traditional Chinese medicine in the treatment of patients infected with 2019new coronavirus (SARS-CoV-2): a review and perspective. Int. J. Biol. Sci. 16,1708-1717.

Yao, X., Zhang, Y., Long, W. and Liu, P. (2012) Oxysophoridine suppresses the growth of hepatocellular carcinoma in mice: in vivo and cDNA microarray studies. Chin. J. Integr. Med. 18, 209-213.

Yi, L., Li, Z., Yuan, K., Qu, X., Chen, J., Wang, G., Zhang, H., Luo, H., Zhu, L., Jiang, P., Chen, L., Shen, Y., Luo, M., Zuo, G., Hu, J., Duan, D., Nie, Y., Shi, X., Wang, W., Han, Y., Li, T., Liu, Y., Ding, M., Deng, H. and Xu, X. (2004) Small molecules blocking the entry of severe acute respiratory syndrome coronavirus into host cells. $J$. Virol. 78, 11334-11339.

You, X., Pan, M., Gao, W., Shiah, H. S., Tao, J., Zhang, D., Koumpouras, F., Wang, S., Zhao, H., Madri, J. A., Baker, D., Cheng, Y. C. and Yin, Z. (2006) Effects of a novel tylophorine analog on collageninduced arthritis through inhibition of the innate immune response. Arthritis Rheum. 54, 877-886.

Yu, M. S., Lee, J., Lee, J. M., Kim, Y., Chin, Y. W., Jee, J. G., Keum, Y. S. and Jeong, Y. J. (2012) Identification of myricetin and scutellarein as novel chemical inhibitors of the SARS coronavirus helicase, nsP13. Bioorg. Med. Chem. Lett. 22, 4049-4054.

Zahedipour, F., Hosseini, S. A., Sathyapalan, T., Majeed, M., Jamial- 
ahmadi, T., Al-Rasadi, K., Banach, M. and Sahebkar, A. (2020) Potential effects of curcumin in the treatment of COVID-19 infection. Phytother. Res. 34, 2911-2920.

Zhang, X., Cai, Y., Zhang, W. and Chen, X. (2018) Quercetin ameliorates pulmonary fibrosis by inhibiting SphK1/S1P signaling. Biochem. Cell Biol. 96, 742-751.

Zhang, Y. N., Zhang, Q. Y., Li, X. D., Xiong, J., Xiao, S. Q., Wang, Z. Zhang, Z. R., Deng, C. L., Yang, X. L., Wei, H. P., Yuan, Z. M., Ye, H. Q. and Zhang, B. (2020) Gemcitabine, lycorine and oxysophoridine inhibit novel coronavirus (SARS-CoV-2) in cell culture. Emerg. Microbes Infect. 9, 1170-1173.
Zhou, Y. B., Wang, Y. F., Zhang, Y., Zheng, L. Y., Yang, X. A., Wang, N., Jiang, J. H., Ma, F., Yin, D. T., Sun, C. Y. and Wang, Q. D. (2012) In vitro activity of cepharanthine hydrochloride against clinical wildtype and lamivudine-resistant hepatitis B virus isolates. Eur. J. Pharmacol. 683, 10-15.

Zhu, N., Zhang, D., Wang, W., Li, X., Yang, B., Song, J., Zhao, X., Huang, B., Shi, W., Lu, R., Niu, P., Zhan, F., Ma, X., Wang, D., Xu, W., Wu, G., Gao, G. F. and Tan, W.; China Novel Coronavirus Investigating and Research Team (2020) A novel coronavirus from patients with pneumonia in China, 2019. N. Engl. J. Med. 382, 727733. 